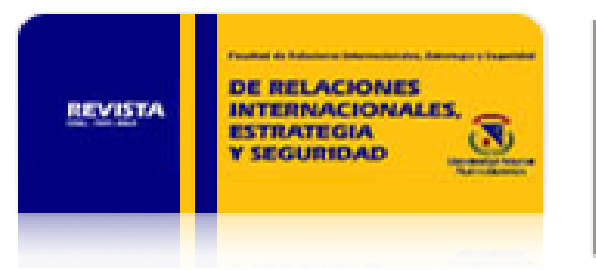

Revista de Relaciones Internacionales, Estrategia y Seguridad

ISSN: 1909-3063

cinuv.relinternal@unimilitar.edu.co

Universidad Militar Nueva Granada

Colombia

Moncayo Jiménez, Edgard

EI TLC de Colombia con Estados Unidos y sus implicaciones en los departamentos colombianos Revista de Relaciones Internacionales, Estrategia y Seguridad, vol. 1, núm. 1, enero-junio, 2006, pp.

177-209

Universidad Militar Nueva Granada

Bogotá, Colombia

Disponible en: http://www.redalyc.org/articulo.oa?id=92710109

- Cómo citar el artículo

- Número completo

- Más información del artículo

- Página de la revista en redalyc.org



Sistema de Información Científica

Red de Revistas Científicas de América Latina, el Caribe, España y Portugal

Proyecto académico sin fines de lucro, desarrollado bajo la iniciativa de acceso abierto 


\title{
El TLC de Colombia con Estados Unidos y sus implicaciones en los departamentos colombianos ${ }^{1}$
}

\author{
Edgard Moncayo Jiménez ${ }^{2}$
}

\begin{abstract}
Resumen
La firma de un TLC con estados representa para Colombia la profundización del modelo de internalización de la economía, que se entronizó a principios de la década pasada, y la definitiva gravitación del país hacia la economía estadounidense.
\end{abstract}

En balance, la estrategia aperturista ha sido hasta ahora francamente decepcionante y conforme a los análisis realizados en este documento, no es realista esperar que el TLC vaya a representar beneficios significativos para el desarrollo nacional. Por el contrario, lo que se advierte es el riesgo de que los desajustes estructurales de la economía colombiana continúen agudizándose (bajo crecimiento, involución del cambio sectorial, desempleo, pobreza y mala distribución del ingreso), agravando de paso los desequilibrios territoriales internos.

Palabras clave: regionalismo, tratados de libre comercio, comercio bilateral, Colombia, Estados Unidos.

Este trabajo hace parte de un estudio más amplio realizado por el autor para la Universidad Autónoma de Colombia, sobre el efecto de la globalización en las regiones colombianas. Fue escrito antes de la suscripción del TLC con Estados Unidos a finales de febrero de 2006, pero sus análisis y conclusiones conservan su vigencia. El autor agradece la valiosa colaboración del economista NésTOR Garza en lo relacionado con el procesamiento estadístico y la elaboración de cuadros y gráficos.

2 Economista, profesor e investigador asociado a varias universidades colombianas. Consultor de Naciones Unidas.edgarmoncayo@yahoo.com 


\begin{abstract}
The signing of a FTA with the United States implies for Colombia the deepening of the internationalization model set up at the beginning of the past decade and the definitive gravitation of the country towards the US economy.

Having been, so far, the results of the liberalization strategy frankly disappointing, it is not realistic - according to the analysis carried out in this article- to expect any substantial benefit for the national development arising from the FTA.

On the contrary, there is the risk of the structural disequilibria of the Colombian economy (slow growth, lack of sectoral change, unemployment, poverty and high inequality of income distribution) to become deeper. In addition, the consolidation of the bilateral trade patterns could worsen the internal territorial polarization as well.
\end{abstract}

Key words: regionalism, FTA, bilateral commerce, Colombia, United States.

\title{
Sumario
}

1. El nuevo regionalismo y el ALCA

2. Los Tratados de Libre Comercio con Estados Unidos

3. El TLC de Colombia con Estados Unidos

3.1. El comercio bilateral de Colombia con Estados Unidos

3.2. Las exportaciones de Colombia hacia Estados Unidos

3.3. Condiciones de acceso de las exportaciones colombianas al mercado de Estados Unidos

3.4. Las importaciones colombianas procedentes de Estados Unidos

4. Implicaciones del TLC con los Estados Unidos hacia los departamentos colombianos

4.1. Las oportunidades de exportación

4.2. La vulnerabilidad departamental frente al eventual aumento de las importaciones 


\section{INTRODUCCIÓN}

La negociación, por parte de Colombia, de un tratado de libre comercio con Estados Unidos, similar al que ya han firmado México, Chile, los Países Centroamericanos, Perú y probablemente suscribirá también Ecuador, se inscribe en un largo proceso de búsqueda de esquemas para alcanzar la integración económica del Continente Americano. En sus etapas iniciales, dicho proceso se circunscribió a América del Sur y tiempo después, se presentó la activa participación de los Estados Unidos.

Es innegable que un acuerdo de libre comercio con la primera potencia económica mundial, tiene consecuencias en el nivel macroeconómico del país y en sus economías subnacionales. El propósito de este trabajo es analizar tales efectos.

\section{EL NUEVO REGIONALISMO Y EL ALCA}

La globalización que por definición supone una intensificación de los flujos comerciales y financieros a escala internacional, ha inducido — en forma paradójica— un resurgimiento del interés en los Acuerdos Regionales de Integración Económica (ARIE). Los ARIE son mecanismos para estimular el comercio en el interior de un conjunto acotado de países.

En los últimos doce años, se han conformado más de la mitad de los 193 ARIE notificados a la OMC (el antiguo GATT), durante el período 1948-2003, 32 de los cuales, son entre países del Continente Americano (BID, 2002).

En el giro favorable hacia el regionalismo, ha pesado con fuerza decisiva, la posición de Estados Unidos que evolucionó desde ser el abanderado del multilateralismo en la posguerra, a constituir en los años noventa el TLCAN (con Canadá y México, sus dos principales socios comerciales), que es un acuerdo regional tanto en términos geográficos como preferenciales, rápidamente convertido en uno de los principales bloques comerciales del mundo (una doctrina Monroe del siglo XXI). También influyó la profundización de la Unión Europea, consagrada en el Tratado de Maastrich de 1992 (Unión Europea), materializada en el Euro y la reciente adhesión de 10 nuevos países. La idea es entonces, que la ampliación o profundización de los acuerdos regionales existentes, insta a los socios comerciales no miembros, a buscar su incorporación para no quedar marginados o a buscar por su cuenta, la formación de otros acuerdos (efecto dominó) $)^{3}$.

La presencia de México en el TLCAN, denota por lo demás, una de las características centrales del nuevo regionalismo, es decir, la asociación entre países de dife-

Véase: BALDWIN, RICHARD, 1993. 
rente grado de desarrollo, sin que haya lugar a tratamientos preferenciales para los menos avanzados (cuando más, diferentes cronogramas de aplicación) ${ }^{4}$.

En términos de su alcance y cobertura, los nuevos acuerdos tienen mayor profundidad en el desmonte arancelario e involucran unas materias que sus homólogos del pasado, no incluían, tales como las sociales y las políticas.

Los rasgos generales del segundo regionalismo arriba descritos, se ajustan bien a lo ocurrido en América Latina en los años noventa. En efecto, mientras que las primeras iniciativas de integración económica emprendidas en la posguerra (ALALC, MCCA, Grupo Andino y CARICOM), se inscribieron en la estrategia de sustitución de importaciones, predominante en la época, el regionalismo abierto de los noventa es funcional a las estrategias de inserción en la economía mundial que han prevalecido en este último período (DeVlin y EstevadeORDAL, 2001).

En síntesis, el contraste entre las dos generaciones de regionalismo mencionadas, puede presentarse así:

\section{Tabla 1}

Regionalismos: primero y segundo

\begin{tabular}{l|l}
\hline \multicolumn{1}{c|}{ Primero } & \multicolumn{1}{c}{ Segundo o abierto } \\
\hline $\begin{array}{l}\text { Funcional a la estrategia de sustitución de } \\
\text { importaciones - un instrumento auxiliar de } \\
\text { la ISI para la ampliación de mercados prote- } \\
\text { gidos-. }\end{array}$ & $\begin{array}{l}\text { Funcional a la estrategia de inserción en la } \\
\text { economía global-tercera vía hacia la libera- } \\
\text { ción mundial de mercados. }\end{array}$ \\
$\begin{array}{l}\text { Acuerdos entre países de grado de desarro- } \\
\text { llo similar. Norte-norte o sur-sur. }\end{array}$ & $\begin{array}{l}\text { Acuerdos entre países desarrollados y menos } \\
\text { avanzados. Norte-sur. }\end{array}$ \\
$\begin{array}{l}\text { Hostilidad de Estados Unidos. } \\
\text { Integración superficial (bienes industriales, } \\
\text { aranceles). }\end{array}$ & $\begin{array}{l}\text { Antegración profunda (todos los productos, } \\
\text { servicios e inversiones, regímenes de com- } \\
\text { petencia). }\end{array}$ \\
$\begin{array}{l}\text { Restricciones a la IED. } \\
\text { Ámbito económico. }\end{array}$ & Ámbito econón de IED. \\
Iniciativa gubernamental. & Participación activa de la empresa privada. \\
\hline
\end{tabular}

Fuente: Elaboración del autor.

4 Sobre el segundo regionalismo latinoamericano véase: MonCAYO (1999) y MonCAYo (2004). 
EL TLC DE COLOMBIA CON ESTADOS UNIDOS Y SUS IMPLICACIONES EN LOS DEPARTAMENTOS COLOMBIANOS

Tabla 2

Acuerdos de comercio suscritos en América 1960 - 2004

\begin{tabular}{|c|c|}
\hline Acuerdo & $\begin{array}{c}\text { Entrada } \\
\text { en vigencia }\end{array}$ \\
\hline $\begin{array}{l}\text { Asociación Latinoamericana de Libre Comercio - ALALC - Transformada } \\
\text { en } 1980 \text { a Asociación Latinoamericana de Integración - ALADI- } \\
\text { (Argentina, Bolivia, Brasil, Chile, Colombia, Ecuador, México, Paraguay, } \\
\text { Perú, Uruguay y Venezuela) }\end{array}$ & 1960 \\
\hline $\begin{array}{l}\text { Mercado Común Centroamericano* } \\
\text { Reformado en } 1993 \\
\text { (El Salvador, Guatemala, Honduras, Nicaragua y Costa Rica }\end{array}$ & 1960 \\
\hline $\begin{array}{l}\text { Acuerdo de Cartagena (Pacto Andino)* } \\
\text { Transformado en } 1996 \text { en la Comunidad Andina }\end{array}$ & 1969 \\
\hline $\begin{array}{l}\text { Caribbean Comunity and Common Market -CARICOM- (Comunidad del } \\
\text { Caribe) } \\
\text { Transformado en } 2002 \text { en la Economía y Mercado Único de la CARICOM } \\
\text { (CARICOM Single Market and Economy - CSME- } \\
\text { (Antigua y Bermuda, Barbados, Jamaica, St Kitts y Nevis, Trinidad y Tobago } \\
\text { (1974), Belice, República Dominicana, Grenada, Monserrat, Santa Lucía, St } \\
\text { Vincent y las Granadinas (1983 y Bahamas (Parte de la Caribean Community } \\
\text { pero no del Mercado Común) }\end{array}$ & 1973 \\
\hline $\begin{array}{l}\text { Chile - México } \\
\text { Chile - Venezuela }\end{array}$ & $\begin{array}{l}1992 \\
1993\end{array}$ \\
\hline $\begin{array}{l}\text { Bolivia - Chile } \\
\text { CARICOM - Venezuela } \\
\text { Tratado de Libre Comercio de América del Norte — TLCAN- }\end{array}$ & $\begin{array}{l}1993 \\
1993 \\
1994\end{array}$ \\
\hline $\begin{array}{l}\text { Mercado Común del Sur —MERCosuR- } \\
\text { Argentina, Brasil, Uruguay y Paraguay }\end{array}$ & $\begin{array}{l}1995 \\
1995\end{array}$ \\
\hline $\begin{array}{l}\text { México - Bolivia } \\
\text { México - Costa Rica } \\
\text { G3 (México, Colombia y Venezuela) } \\
\text { CARICOM - Colombia } \\
\text { Chile - Ecuador } \\
\text { Chile - MERCosur } \\
\text { Bolivia - MERCosur } \\
\text { Canadá - Chile } \\
\text { Chile - Perú }\end{array}$ & $\begin{array}{l}1995 \\
1995 \\
1995 \\
1995 \\
1995 \\
1996 \\
1997 \\
1997 \\
1998\end{array}$ \\
\hline
\end{tabular}




\begin{tabular}{l|c}
\hline \multicolumn{1}{c|}{ Acuerdo } & $\begin{array}{c}\text { Entrada } \\
\text { en vigencia }\end{array}$ \\
\hline Centroamérica - República Dominicana & 1998 \\
México - Nicaragua & 1998 \\
México - Chile & 1999 \\
México - Uruguay & 2000 \\
México - Perú & 2000 \\
Colombia, Ecuador, Perú y Venezuela - Argentina & 2000 \\
México - Honduras, Guatemala y El Salvador & 2001 \\
Chile - Centroamérica & 2002 \\
Canadá - Costa Rica & 2002 \\
Perú - MERcosur & 2003 \\
Estados Unidos - Chile & 2004 \\
can - mercosur & 2004 \\
Estados Unidos - Centroamérica** & 2005 \\
\hline
\end{tabular}

* Estos acuerdos buscaban formar una Unión Aduanera e incluso un mercado común.

** Pendiente de aprobación parte del Congreso de Estados Unidos.

Fuente: Elaboración del autor con base en el Sistema de Información de Comercio Exterior de la oEA y otras fuentes.

La conformación del TLCAN en 1994, desencadenó una oleada de ARIE de segunda generación en América Latina. Entre 1960 (año de creación de la ALALC), y 1994 se suscribieron ocho ARIE, mientras que entre este año y 2004, se formaron 23 (tabla 2). Además, los cinco ARIE del primer regionalismo se "abrieron" para acoger el modelo del segundo.

La densa trama de acuerdos entre las naciones americanas ${ }^{5}$ — que ha dado lugar a la metáfora del "plato de fideos" o spaghetti bowl- parecía rumbo a alcanzar su plena culminación en el marco de la Asociación de Libre Comercio de las Américas (ALCA), conformada por 34 países del Hemisferio occidental (sin Cuba). La entrada en vigencia del ALCA estaba prevista para 2005.

Para Estados Unidos, el ALCA representa ampliar el TLCAN a un territorio que vaya desde Anchorage hasta la Tierra del Fuego, según el designio formulado en la convocatoria lanzada por el presidente Bush en la Iniciativa de las Américas (1990). Con este bloque, los Estados Unidos podrían oponer su propio regionalismo a los regionalismos cada vez más abarcantes de la Unión Europea y la APEC, y de paso, afianzarían su presencia en una zona que por tradición ha estado en su área de influencia.

Un examen comparativo de los contenidos y alcances de los ARIE posteriores al TLCAN se encuentra en: Jesús Alberto Villamil y Fernando Estupiñán, 2004. 
Como dice Dornbush (1995: 48):

Estados Unidos tiene en el ALCA la oportunidad de consolidar las reformas, diseminar la cultura de mercado y promover la democracia en América Latina, contribuyendo de este modo a su propia seguridad nacional ${ }^{6}$.

El proceso de negociaciones tendiente a establecer el ALCA, se inició en 1994 (Cumbre de las Américas en Miami), y después de dos cumbres presidenciales más y cinco reuniones ministeriales, se llegó en 2001 (V Reunión Ministerial en Buenos Aires), a un primer borrador de acuerdo ${ }^{7}$.

A partir de este momento, la atmósfera de las negociaciones se enrareció notablemente, debido entre otras razones, al ambiente político adverso a la liberación comercial en Estados Unidos ${ }^{8}$ y a la decisión de este país de trasladar temas como las ayudas internas y los subsidios a las exportaciones, a las negociaciones de la Ronda de Doha, en el marco de la omc.

Como consecuencia de lo anterior, tanto en la VI y VII reunión ministerial, celebradas en Quito (2002) y Miami (2003) respectivamente, no se evidenció algún avance sustantivo hacia el establecimiento del ALCA en $2005^{\circ}$. Antes bien, el fracaso de la Ronda de Doha en Cancún (2003), sacó nuevamente a flote en el contexto del ALCA, los asuntos relativos a los subsidios, el antidumping y las ayudas a la agricultura que Estados Unidos había anunciado que negociaría en el marco de la omc, y que de tiempo atrás, eran contenciosos en las negociaciones del ALCA.

El estancamiento de las negociaciones abrió las puertas, a partir de 2002, a dos vertientes de integración comercial en el Hemisferio occidental, que si bien en teoría son compatibles, en la práctica tienen un alto potencial de colisión: a) los acuerdos bilaterales de países latinoamericanos con Estados Unidos; y b) el fortalecimiento de los vínculos intrasuramericanos.

En cuanto a lo primero, Chile y los Países Centroamericanos firmaron en 2002 y 2003 respectivamente, sendos acuerdos bilaterales con Estados Unidos; y Colombia, Ecuador y Perú iniciaron en 2004, negociaciones tendientes al mismo fin. De esta manera, Estados Unidos logró imponer en la práctica, la estrategia de divide y

6 DORNBUSH, RUDIGER, 1995.

7 Un análisis de la dinámica de la negociación y de los distintos intereses nacionales en juego se encuentra en: Herminio Blanco y Jaime Zabludovsky, 2003.

8 Como se hizo evidente con el dilatado y engorroso proceso de la Trade Promotion Authority — TPA— en el Congreso estadounidense.

9 El intento de reactivar las negociaciones en el marco de la IV Cumbre de las Américas (al nivel presidencial), celebrado en noviembre de 2005 en Mar del Plata, fue un estruendoso fracaso, debido a las posiciones antagónicas de México (en pro) y Mercosur (en contra). 
reinarás, al negociar condiciones diferentes para cada grupo de países que no había logrado avanzar en el ALCA. Con respecto de la intensificación de los lazos en el Continente Suramericano, volveremos más adelante.

\section{LOS TRATADOS DE LIBRE COMERCIO CON ESTADOS UNIDOS}

El análisis de la experiencia de los TLC suscritos con Estados Unidos, revela resultados por lo menos ambiguos. En efecto, aunque varios estudios encuentran que el TLCAN ha tenido efectos positivos en la economía mexicana, sobre todo en términos del aumento en las exportaciones y de la $\operatorname{IED}^{10}$, esta apreciación debe cualificarse en cuanto a lo siguiente ${ }^{11}$ :

a) Si bien las exportaciones de México hacia Estados Unidos fueron más que duplicadas entre 1995 y 2003 (pasaron de US61.705 millones a US138.073 millones), ello no se tradujo en una aceleración semejante en las tasas de crecimiento del PIB, pues en ese mismo período, se situaron apenas en el promedio latinoamericano $(2,9 \% \text { anual entre } 1995 \text { y } 2004)^{12}$.

b) Desde 2002, el crecimiento del PIB y el de las exportaciones están estancados (TORNell et al., 2004).

c) La competitividad sistémica del país (posición en el ranking del World Economic Forum), en lugar de haber mejorado, se ha deteriorado.

d) Las importaciones totales (del mundo), crecieron aún más rápidamente que las exportaciones, por lo tanto, el balance en cuenta corriente ha sido permanentemente deficitario en el período que se está analizando.

e) Las exportaciones de maquila, que desde 1998 son un poco más de la mitad del total, tienen un contenido importado cercano al $80 \%$. Además, las exportaciones netas de maquila han permanecido en el mismo nivel desde 1998.

f) Desde 2000, China — que no tiene un TLC— superó a México como proveedor de Estados Unidos, registrando una participación en este mercado del 12,04\% (la de México es de 11,4\%), con el agravante de que la oferta exportable de los dos países tiene un altísimo y creciente porcentaje de traslape (60\% en la actualidad). Además, en 2003. la participación de México en el mercado de Estados Unidos fue de 11,4\%, inferior al 11,8\% de 1994.

10 Véase por ejemplo: Kose, M. Ayhan et al. (2004). y Lederman, Daniel et al., 2005.

11 Las cifras en las que basan las apreciaciones que siguen son tomadas de: René ViLLARREAL, 2004.

12 Sobre este punto véase: Juan Ramiro De La Rosa, 2001. 
g) El análisis econométrico muestra que no hay evidencia empírica de que el TLCAN haya tenido efectos significativos sobre la inversión extranjera de cartera, porque mucho antes de que el TLC entrara en vigencia, el mercado de capitales de México ya estaba casi perfectamente integrado con el estadounidense (VENEGASMARTíneZ, 2004). Además, la IED que se ha producido, se ha concentrado en unos pocos sectores - entre los cuales destaca el financiero- y en un alto porcentaje, se ha orientado hacia adquisiciones de empresas existentes.

h) El modelo de apertura mexicano ha incrementado la desigualdad y la extrema pobreza, no la pobreza total (Morley y Díaz Bonilla, 2004).

i) Por último, dado que el ciclo económico de México está cada vez más sincronizado con el de Estados Unidos (este país absorbe el $90 \%$ de las exportaciones mexicanas), la reciente recesión estadounidense determinó el estancamiento del crecimiento económico y de las exportaciones mexicanas.

En síntesis, según la opinión de Villarreal (2004: 172), la lección de la experiencia de México en el TLCAN se puede resumir así: "La apertura pasiva mediante acuerdos de libre comercio con una política industrial pasiva, conducen a un modelo exportador de manufacturas de ensamble dinámico, con desarticulación productiva interna no sustentable".

En cierto modo, esta opinión coincide con otra más ortodoxa (ToRnell et al. op. cit.: 34, traducción libre del autor), según la cual:

La experiencia mexicana sugiere que el crecimiento de largo plazo no puede basarse solamente en el crecimiento de las exportaciones, porque el sector transable depende de insumos no transables, y por tanto, es necesario que el sector que produce estos últimos también crezca para asegurar una senda de crecimiento balanceada y sostenible.

Es pertinente señalar que si bien es cierto, México concibió al inicio (principios de los noventa), el TLC con Estados Unidos como parte esencial de una nueva estrategia de desarrollo (basada en las exportaciones), en la actualidad ya tiene zonas de libre comercio con los mercados más importantes del mundo desarrollado: Unión Europea (2000), y Asociación Europea de Libre Comercio (2001). El único país desarrollado con el cual México todavía no tiene un TLC es Japón, país que en 2001 contribuyó con el $2,7 \%$ del total del comercio exterior mexicano ${ }^{13}$.

En cuanto al TLC de Chile con Estados Unidos ${ }^{14}$, firmado en 2003 y vigente desde 2004, es aún muy temprano para emitir juicios documentados sobre sus re-

13 Para un completo análisis de los acuerdos de libre comercio de México con los países desarrollados véase: Alicia PuYAna, 2003.

14 Para una completa descripción del contenido y alcances de este tLC véase: Germán UMAÑA, 2003. 
sultados. No obstante, cabe señalar que al contrario de México (en la fase inicial), Centroamérica y los Países Andinos, Chile concibe el TLC con Estados Unidos no como una estrategia de desarrollo sino como un eslabón adicional dentro su estrategia de liberación comercial, que se agrega a los acuerdos que ya tiene con Canadá, la Unión Europea, la Asociación Europea de Libre Comercio (EFTA), Corea del Sur y la mayoría de los países latinoamericanos, incluido México.

En tales circunstancias y dado el hecho de que Chile partió en un nivel de protección más reducido que el de México y Colombia, la mayoría de los estudios realizados sobre el tema, coincide en señalar que el impacto sobre el PIB chileno estará en un lánguido rango que va del 0,2 al 1\% (CABEZAS, 2003 y CHUMACERO et al., 2004).

Siguiendo la lógica de no quedarse por fuera del tren del libre comercio con Estados Unidos, es decir, de asegurar el mismo acceso al mercado estadounidense que ya tienen otros países latinoamericanos, Colombia, Perú y Ecuador iniciaron en mayo de 2004, negociaciones tendientes a suscribir acuerdos con esa nación ${ }^{15}$. En este caso, no se trata de un solo tratado plurilateral, sino de tres diferentes que se negocian al mismo tiempo.

Hasta el momento, se han realizado 8 reuniones de negociación: Cartagena, mayo de 2004; Atlanta, junio de 2004; Lima, julio de 2003; Fajardo, septiembre de 2004; Guayaquil, octubre de 2004; Tucson, noviembre - diciembre de 2004; Cartagena, febrero de 2005 y Washington D.C., marzo de 2005.

En las negociaciones comerciales entre los países andinos mencionados y Estados Unidos, se juegan intereses que en algunos aspectos son coincidentes (o complementarios), y en otros contrapuestos.

En la perspectiva de Estados Unidos, el tema de los TLC es contundentemente inequívoco: se trata de un asunto de seguridad nacional. Así lo dice textualmente la Ley de Comercio de 2002 (Trade Promotion Authority Act):

(1) The expansion of international trade is vital to the national security of the United States. Trade is critical to the economic growth and strength of the United States and to its leadership in the world. Stable trading relationships promote security and prosperity. Trade agreements today serve the same purposes that security pacts played during the Cold War, binding nations together through a series of mutual rights and obligations. Leadership by the United States in international trade fosters open markets, democracy, and peace throughout the world.

(2) The national security of the United States depends on its economic security, which in turn is founded upon a vibrant and growing industrial base. Trade expansion has been the engine of economic growth. Trade agreements maximize opportunities for the critical sectors and buil-

15 En marzo de este año (2005), Bolivia oficializó en Washington su interés de unirse a la negociación. 
EL TLC DE COLOMBIA CON ESTADOS UNIDOS Y SUS IMPLICACIONES EN LOS DEPARTAMENTOS COLOMBIANOS

ding blocks of the economy of the United States, such as information technology, telecommunications and other leading technologies, basic industries, capital equipment, medical equipment, services, agriculture, environmental technology, and intellectual property. Trade will create new opportunities for the United States and preserve the unparalleled strength of the United States in economic, political, and military affairs. The United States, secured by expanding trade and economic opportunities, will meet the challenges of the twenty-first century.

En lo que hace relación específica con Colombia, Ecuador y Perú, estos son países que no representan mucho para las exportaciones ni para la IED de Estados Unidos, sino que son considerados por este país, como puntos estratégicos para la seguridad de la Región Andina. Los costos que tendría que pagar Estados Unidos para lograr sus objetivos en el área andina no son mayores, según la mayoría de los estudios realizados al respecto, entre otras cosas, porque actualmente el arancel ponderado aplicable a las exportaciones procedentes de esta zona es sólo del orden del $0,8 \%{ }^{16}$. Esto, debido a que un alto porcentaje de la oferta exportable de Colombia, Ecuador y Perú está constituido por materias primas y productos básicos que no son objeto de gravámenes arancelarios y a las preferencias unilaterales del ATPDEA $^{17}$.

Ahora analizaremos el TLC de Colombia con Estados Unidos, en el contexto de los flujos comerciales entre los dos países.

\section{EL TLC DE COLOMBIA CON LOS ESTADOS UNIDOS}

Colombia, que ha participado activamente en todos los procesos de integración latinoamericana (ALCA, CAN, G3 y Comunidad Suramericana de Naciones ${ }^{18}$ ), se apresta ahora a firmar un TLC con los Estados Unidos. En la perspectiva de la actual administración, este tratado es benéfico para el país por las siguientes razones ${ }^{19}$ :

A. El TLC estimulará las exportaciones a Estados Unidos, y por lo tanto, tendrá un impacto positivo en el crecimiento y el ingreso per cápita.

B. EL TLC — por medio del crecimiento— reducirá la pobreza.

C. El TLC propiciará el crecimiento del sector agrícola.

16 El arancel promedio para México es 0,34\% y para el mundo (NMF) de 3,1\%.

$17 \quad$ El atPDEA (Andean Trade Referents and Drug Erradication Act) consagra preferencias unilaterales de Estados Unidos a favor de Bolivia, Colombia, Ecuador y Perú, como reconocimiento de dicho país a la responsabilidad compartida que le cabe en la lucha contra el cultivo y tráfico de drogas ilícitas.

18 CAN + miembros del Mercosur.

19 Véase: Ministerio de Comercio, Industria y Turismo, 2005. 
Como puede observarse, los argumentos de la administración Uribe son en esencia los mismos que esgrimió la administración Gaviria para sustentar la apertura de principios de los noventa. Conociendo ya cuáles fueron los verdaderos resultados de las políticas aperturistas y ante la falta absoluta de consenso académico sobre la supuesta cadena causal apertura aumento de las exportaciones ${ }^{\circledR}$ aumento del PIB per cápita ${ }^{\circledR}$ reducción de la pobreza, no se entiende por qué el gobierno colombiano pretende que el TLC (más de lo mismo), es la estrategia salvadora para los graves problemas que aquejan a la economía nacional ${ }^{20}$.

La perplejidad aumenta cuando se comprueba que los estudios elaborados en instituciones gubernamentales como el Banco de la República y el DNP, tampoco permiten ser muy optimistas acerca de los supuestos beneficios del TLC, veamos:

A. El impacto sobre el crecimiento: MarTín y Ramírez (2005) ${ }^{21}$, sostienen que los efectos positivos dependen críticamente del grado en que se logren desmontar las barreras no arancelarias (BNA), en Estados Unidos. Por su parte, BотERO y LÓPEZ (2005) $)^{22}$ encuentran que los efectos del TLC son importantes, pero transitorios, porque tienden a diluirse con el tiempo.

B. Efecto sobre el comercio exterior: el eventual impacto positivo que detectan MARTín y RAMírez (op. cit.), sobre el crecimiento, se da por medio de un incremento en las exportaciones que sólo se producirá — - según ellos mismos— si se logra una disminución sustantiva de las BNA (barreras no arancelarias), en Estados Unidos. Para CÁrdenas y García (2004), en cambio, que se valen de un modelo de equilibrio general, no existen condiciones para que el TLC produzca un aumento de hasta el $200 \%$ (!) en las exportaciones a Estados Unidos y del $40 \%$ en el comercio bilateral.

C. Impacto sobre el empleo: un estudio de Botero y LÓPEZ (op. cit.), estima un crecimiento del $1,7 \%$ en el empleo generado y de hasta el $2,5 \%$, si el país hace

20 Algunos analistas han sugerido que la posición negociadora colombiana se ha subordinado al interés de lograr el apoyo de Estados Unidos a la política de seguridad democrática de la administración Uribe Vélez, véase por ejemplo (PARDo, 2004 y García, 2004. Otros ven en el tLC la oportunidad de hacer irreversibles a través de un tratado internacional las reformas de los noventa (lock-in effect) y de globalizar nuestras prácticas económicas y culturales, poniéndolas a tono con las exigencias de la mundialización (CLAVIJO, 2004).

21 Martín, Clara Patricia y Ramírez, Juan Mauricio (2005). A este respecto, Vaughan (2005), considera que en el evento hipotético de que Estados Unidos elimine las BNA a todos los países del mundo, las ganancias para Colombia serían nulas o incluso negativas, porque el flujo de comercio quedaría determinado solamente por las ventajas comparativas de cada país. En este escenario, China se quedaría, por ejemplo, con la mayor parte del mercado estadounidense de textiles.

22 Botero, Jesús y López, Hugo, 2005. 
un importante esfuerzo de capacitación de la mano de obra ${ }^{23}$. Estos montos serían el resultado de una recomposición sectorial en el empleo, en cuyo contexto, uno de los sectores perdedores sería la agricultura.

D. Efecto sobre la pobreza y la distribución del ingreso: los dos trabajos que inciden sobre este tema, presentan resultados contradictorios. Así, mientras MARTín y RAMíREZ (op. cit.), prevén efectos positivos porque supuestamente el TLC beneficiaría a los sectores intensivos en trabajo no calificado e informal y en trabajo formal (sic), Botero y LóPEz (op. cit.) —en línea con la mayoría de los estudios sobre esta materia - encuentran que el tratado beneficiará al trabajo calificado en mayor medida.

Llama la atención el hecho de que ninguno de los estudios mencionados, toma en cuenta el efecto adverso que puede tener sobre la producción nacional, el aumento de las importaciones procedentes de Estados Unidos.

Con todo, la revisión de la literatura académica sobre el TLC de Colombia con los Estados Unidos, deja la impresión de que los efectos del tratado no son significativos en manera alguna para el desarrollo del país ${ }^{24}$.

En tal sentido, el balance de los estudios realizados está bien reflejado por Bussolo y RoLAND-Holst (2002: 239, el énfasis es añadido) ${ }^{25}$ en la siguiente conclusión:

\begin{abstract}
Las ventajas para Colombia de su ingreso al TLC, sin embargo, podrían tener como contrapartida negativa la intensificación de las pautas tradicionales de las ventajas comparativas del país (...) es importante resaltar (...) que es poco probable que la apertura de mercados por sí sola lleve al país a una importante trayectoria de crecimiento sustentable. Las reformas externas deben coordinarse con políticas internas de formación e inversión del capital humano que fomenten las externalidades del crecimiento y la modernización (...).
\end{abstract}

\title{
3.1. El comercio bilateral de Colombia con los Estados Unidos
}

En el período posapertura (1991-2003), el comercio de doble vía de Colombia con Estados Unidos, creció a una tasa promedio anual del 7,0\%, que es un nivel muy superior al crecimiento del comercio mundial de 6,5\%), pero muy similar al de la expansión de los intercambios del país con el resto del mundo (gráfico 1).

\footnotetext{
23 Acerca de estos cálculos, Gaviria (2005: 2) dice que "están basados en una serie de supuestos exógenos que los convierten más en opiniones que en proyecciones".

24 Una apreciación similar se expresa en: GaviRIA (2005, op. cit.). En el mismo sentido concluye un estudio sobre el impacto del tLC en Perú (2005), Costos y beneficios del TLC con Estados Unidos, Lima, Friedrich Ebert Stiftung / Red Latinoamericana de Comercio Internacional — LATN-.

25 Bussolo, Mauricio y David Roland-Holst, 2002.
} 


\section{Gráfico 1}

Colombia: Dinamismo del comercio con Estados Unidos 1991-2003

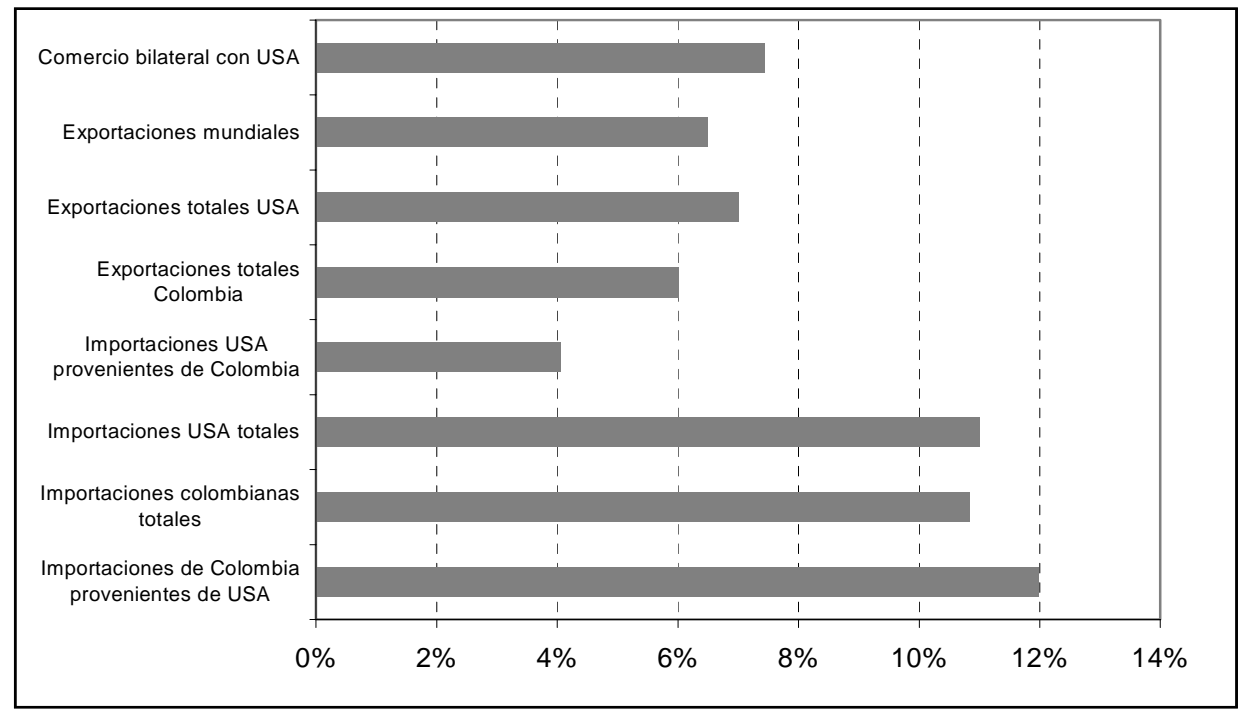

Fuente: DANE, USTIC, OMC

En el marco del intercambio entre los dos países, las importaciones han crecido a un ritmo similar al de las exportaciones en el período completo 1991-2003, pero con una balanza comercial negativa para Colombia en el lapso 1993-1998 y positiva desde 1999 en adelante (cuadro 1 y gráfico 2).

En el gráfico 2, se observa además, que la balanza comercial con Estados Unidos en la fase posapertura (salvo en 1991 y 1992), ha sido más favorable (más positiva o menos negativa), para Colombia que la registrada con el resto del mundo, lo cual contrasta con el subperíodo 1977-1990, en el cual, la situación era al revés. A este respecto, llama especialmente la atención los apreciables saldos positivos con Estados Unidos a partir de 1999, en comparación con los crecientes resultados negativos frente al resto del mundo.

Tal comportamiento es consecuencia, por una parte, del fuerte ajuste hacia abajo que sufrieron las importaciones procedentes de Estados Unidos, a raíz de la recesión de 1999 y por otra, del fortalecimiento de las exportaciones minerales de Colombia hacia ese mercado. El efecto de esto último se aprecia claramente al observar el cuadro 2 que muestra que por sectores, la balanza relativa es ampliamente favorable para el sector minero, en tanto que en el sector industrial es negativa, en todo el período analizado. Por su parte, el sector agropecuario presenta saldos favorables, pero decrecientes. 
ELTLC DE COLOMBIA CON ESTADOS UNIDOS Y SUS IMPLICACIONES EN LOS DEPARTAMENTOS COLOMBIANOS

\section{Cuadro 1}

Colombia: comercio con Estados Unidos 1977-2003

\begin{tabular}{|c|c|c|c|c|}
\hline Años & Exportaciones & Importaciones & $\begin{array}{c}\text { Comercio } \\
\text { total }\end{array}$ & $\begin{array}{c}\text { Balanza } \\
\text { comercial }\end{array}$ \\
\hline 1977 & 690.1 & 668.9 & 1359.0 & 21.2 \\
\hline 1978 & 858.3 & 884.8 & 1743.2 & -26.5 \\
\hline 1979 & 968.8 & 1140.4 & 2109.2 & -171.6 \\
\hline 1980 & 1053.3 & 1617.0 & 2670.3 & -563.7 \\
\hline 1981 & 678.3 & 1563.4 & 2241.7 & -885.1 \\
\hline 1982 & 696.1 & 1676.4 & 2372.5 & -980.3 \\
\hline 1983 & 849.9 & 1560.6 & 2410.5 & -710.7 \\
\hline 1984 & 1068.8 & 1362.5 & 2431.2 & -293.7 \\
\hline 1985 & 1130.5 & 1233.0 & 2363.5 & -102.6 \\
\hline $1986 *$ & 1449.6 & 0.0 & 1449.6 & 0.0 \\
\hline 1987 & 1877.8 & 1352.0 & 3229.8 & 525.8 \\
\hline 1988 & 1841.1 & 1621.0 & 3462.1 & 220.1 \\
\hline 1989 & 2343.2 & 1669.1 & 4012.2 & 674.1 \\
\hline 1990 & 2793.0 & 1802.7 & 4595.7 & 990.2 \\
\hline $\begin{array}{l}\text { Crecimiento } \\
\text { promedio anual } \\
1977-1990\end{array}$ & $11 \%$ & $8 \%$ & $10 \%$ & $34 \%$ \\
\hline 1991 & 2517.9 & 1660.7 & 4178.5 & 857.2 \\
\hline 1992 & 2466.1 & 2233.7 & 4699.7 & 232.4 \\
\hline 1993 & 2639.7 & 3201.7 & 5841.4 & -561.9 \\
\hline 1994 & 2972.3 & 3986.9 & 6959.2 & -1014.6 \\
\hline 1995 & 3542.9 & 4719.4 & 8262.3 & -1176.5 \\
\hline 1996 & 4088.9 & 4853.5 & 8942.4 & -764.6 \\
\hline 1997 & 4262.3 & 5501.3 & 9763.6 & -1239.0 \\
\hline 1998 & 4048.5 & 4807.5 & 8856.1 & -759.0 \\
\hline 1999 & 5615.5 & 3853.3 & 9468.8 & 1762.2 \\
\hline 2000 & 6527.4 & 3999.6 & 10527.0 & 2527.8 \\
\hline 2001 & 5254.3 & 4502.0 & 9756.2 & 752.3 \\
\hline 2002 & 5151.2 & 4082.4 & 9233.6 & 1068.8 \\
\hline 2003 & 5758.2 & 3853.9 & 9612.2 & 1904.3 \\
\hline $\begin{array}{l}\text { Crecimiento } \\
\text { promedio anual }\end{array}$ & $7 \%$ & $7 \%$ & $7 \%$ & $7 \%$ \\
\hline
\end{tabular}

Fuente: Elaboración propia con base en DANE. 
Gráfico 2

Colombia: balanzas comerciales

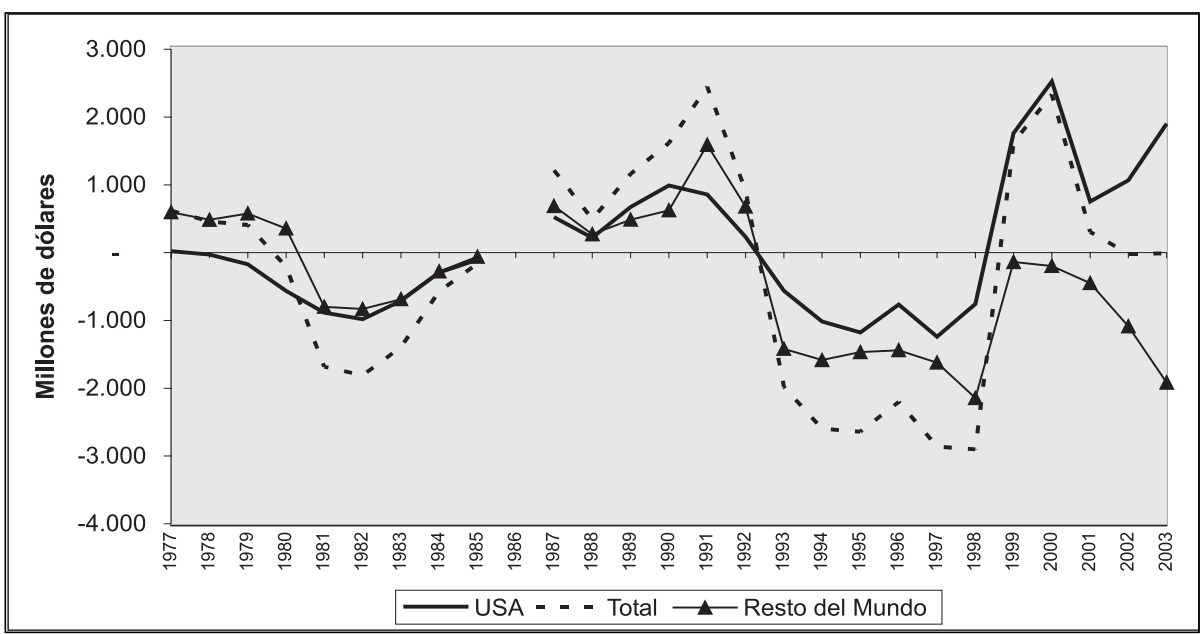

Fuente: Cálculos del autor con base en información del DANE

Cuadro 2

Balanza Comercial Relativa de Colombia con USA

\begin{tabular}{|c|c|c|c|c|c|c|c|c|c|c|c|c|}
\hline & 1991 & 1992 & 1993 & 1994 & 1995 & 1996 & 1997 & 1998 & 1999 & 2000 & 2001 & 2002 \\
\hline Agropec. & 48.2 & 51.3 & 51.4 & 48.6 & 31.1 & 5.9 & 20.2 & 23.4 & 30.6 & 35.0 & 36.8 & 24.9 \\
\hline Minería & 97.6 & 97.1 & 97.0 & 97.0 & 97.5 & 98.0 & 98.3 & 98.7 & 98.9 & 99.4 & 99.6 & 99.3 \\
\hline Industria & -11.0 & -27.9 & -42.8 & -50.2 & -50.5 & -47.8 & -53.0 & -43.4 & -39.9 & -32.8 & -33.5 & -29.6 \\
\hline Otros & -62.3 & 35.2 & 73.3 & -41.3 & -0.7 & 14.0 & 66.0 & 72.0 & 56.9 & 28.5 & 19.5 & -9.5 \\
\hline Total & 23.5 & 4.7 & -12.3 & -17.8 & -21.8 & -15.4 & -13.2 & -4.7 & 1.2 & 18.1 & 19.3 & 13.1 \\
\hline \multirow{2}{*}{\multicolumn{7}{|c|}{ La balanza comercial relativa se calcula con la fórmula: }} & $\mathrm{X}-\mathrm{M}$ & \multirow{2}{*}{ • 100} & & & & \\
\hline & & & & & & & $Y+M$ & & & & & \\
\hline
\end{tabular}

Fuente: Elaboración propia con base en DANE.

Lo anterior quiere decir que el intercambio comercial de Colombia con Estados Unidos responde a un patrón típico norte-sur (productos primarios por bienes industriales), que se ciñe estrictamente al modelo de ventajas comparativas de los libros de texto. Este patrón — que no es favorable para el desarrollo mediante el cambio estructural - podría acentuarse aún más, como consecuencia del TLC, tal como lo señalan Bussolo y Roland-Holst (op. cit.). 
EL TLC DE COLOMBIA CON ESTADOS UNIDOS Y SUS IMPLICACIONES EN LOS DEPARTAMENTOS COLOMBIANOS

\subsection{Las exportaciones de Colombia hacia Estados Unidos}

Entre 1991 y 2003, la participación de Estados Unidos en las ventas externas de Colombia aumentó de 38 a 44\%, con lo cual, el mercado norteamericano se consolidó como el más importante para el país (cuadro 3).

Cuadro 3

Participación de Estados Unidos en las exportaciones colombianas (millones de dólares)

\begin{tabular}{lrrr}
\hline & USA & Totales & \% USA \\
\hline 1990 & 2.782 & 6.720 & 41,4 \\
1991 & 2.782 & 7.244 & 38,4 \\
1992 & 2.554 & 7.065 & 36,1 \\
1993 & 2.534 & 7.123 & 35,6 \\
1994 & 2.653 & 8.538 & 31,1 \\
1995 & 2.991 & 10.201 & 29,3 \\
1996 & 3.527 & 10.648 & 33,1 \\
1997 & 4.141 & 11.549 & 35,9 \\
1998 & 4.262 & 10.866 & 39,2 \\
1999 & 4.049 & 11.617 & 34,8 \\
2000 & 5.616 & 13.158 & 42,7 \\
2001 & 6.524 & 12.330 & 52,9 \\
2002 & 5.255 & 11.975 & 43,9 \\
\hline
\end{tabular}

Fuente: Elaboración propia con base en DANE

Como ya se ha sugerido, en la corriente exportadora hacia Estados Unidos, predominan los productos mineros (50\% del total en 2002), seguidos por los industriales y, en un lejano tercer lugar, por los agropecuarios (cuadro 4). Esta estructura exportadora contrasta de manera desfavorable con la de las ventas a la CAN, en la cual existe un predominio casi exclusivo de las manufacturas (cuadro 5). Incluso, comparado con el patrón de exportaciones al mundo, el de Estados Unidos es el más sesgado hacia productos primarios (cuadro 6).

\section{Cuadro 4}

\section{Composición de exportaciones a USA por sectores}

\begin{tabular}{lrrrrrrrrrrrrr}
\hline & $\mathbf{1 9 9 0}$ & $\mathbf{1 9 9 1}$ & $\mathbf{1 9 9 2}$ & $\mathbf{1 9 9 3}$ & $\mathbf{1 9 9 4}$ & $\mathbf{1 9 9 5}$ & $\mathbf{1 9 9 6}$ & $\mathbf{1 9 9 7}$ & $\mathbf{1 9 9 8}$ & $\mathbf{1 9 9 9}$ & $\mathbf{2 0 0 0}$ & $\mathbf{2 0 0 1}$ & $\mathbf{2 0 0 2}$ \\
\hline Agropecuario & 7 & 7 & 15 & 16 & 19 & 19 & 15 & 13 & 14 & 15 & 12 & 10 & 13 \\
Minería & 35 & 46 & 36 & 33 & 36 & 33 & 41 & 49 & 46 & 47 & 56 & 58 & 50 \\
Industria & 42 & 47 & 48 & 49 & 45 & 48 & 43 & 37 & 40 & 38 & 32 & 31 & 37 \\
Otros & 0 & 0 & 1 & 1 & 0 & 0 & 0 & 0 & 0 & 0 & 0 & 0 & 0 \\
\hline
\end{tabular}

Fuente: Elaboración propia con base en DANE. 


\section{Cuadro 5}

Composición de exportaciones a la CAN por sectores

\begin{tabular}{lrrrrrrrrrrrrr}
\hline & $\mathbf{1 9 9 0}$ & $\mathbf{1 9 9 1}$ & $\mathbf{1 9 9 2}$ & $\mathbf{1 9 9 3}$ & $\mathbf{1 9 9 4}$ & $\mathbf{1 9 9 5}$ & $\mathbf{1 9 9 6}$ & $\mathbf{1 9 9 7}$ & $\mathbf{1 9 9 8}$ & $\mathbf{1 9 9 9}$ & $\mathbf{2 0 0 0}$ & $\mathbf{2 0 0 1}$ & $\mathbf{2 0 0 2}$ \\
\hline Agropecuario & 3 & 7 & 6 & 3 & 3 & 3 & 1 & 1 & 4 & 3 & 3 & 3 & 2 \\
Minería & 8 & 9 & 10 & 5 & 2 & 14 & 14 & 11 & 7 & 8 & 6 & 1 & 2 \\
Industria & 88 & 83 & 84 & 92 & 96 & 83 & 84 & 88 & 89 & 89 & 92 & 96 & 96 \\
Otros & 0 & 1 & 0 & 0 & 0 & 0 & 0 & 0 & 0 & 0 & 0 & 0 & 0 \\
\hline
\end{tabular}

Fuente: Elaboración propia con base en DANE.

\section{Cuadro 6}

\section{Composición de exportaciones totales por sectores}

\begin{tabular}{lrrrrrrrrrrrrr}
\hline & $\mathbf{1 9 9 0}$ & $\mathbf{1 9 9 1}$ & $\mathbf{1 9 9 2}$ & $\mathbf{1 9 9 3}$ & $\mathbf{1 9 9 4}$ & $\mathbf{1 9 9 5}$ & $\mathbf{1 9 9 6}$ & $\mathbf{1 9 9 7}$ & $\mathbf{1 9 9 8}$ & $\mathbf{1 9 9 9}$ & $\mathbf{2 0 0 0}$ & $\mathbf{2 0 0 1}$ & $\mathbf{2 0 0 2}$ \\
\hline Agropecuario & 4 & 11 & 12 & 12 & 12 & 10 & 10 & 10 & 11 & 10 & 9 & 9 & 10 \\
Minería & 31 & 24 & 24 & 24 & 19 & 25 & 31 & 28 & 28 & 36 & 37 & 31 & 30 \\
Industria & 65 & 64 & 63 & 63 & 69 & 65 & 59 & 62 & 61 & 53 & 54 & 60 & 60 \\
Otros & 0 & 1 & 1 & 0 & 0 & 0 & 0 & 0 & 0 & 0 & 0 & 0 & 0
\end{tabular}

Fuente: Elaboración propia con base en DANE.

\section{Cuadro 7}

\begin{tabular}{lccccccc}
\hline & Colombia & Chile & México & Venezuela & Brasil & Argentina & 6 países \\
\hline 1990 & 0.64 & 0.26 & 6.05 & 1.90 & 1.58 & 0.30 & 10.74 \\
1991 & 0.56 & 0.27 & 6.34 & 1.67 & 1.37 & 0.26 & 10.46 \\
1992 & 0.53 & 0.26 & 6.56 & 1.52 & 1.42 & 0.23 & 10.53 \\
1993 & 0.51 & 0.25 & 6.77 & 1.38 & 1.27 & 0.20 & 10.39 \\
1994 & 0.47 & 0.27 & 7.40 & 1.25 & 1.30 & 0.26 & 10.96 \\
1995 & 0.51 & 0.26 & 8.29 & 1.30 & 1.18 & 0.23 & 11.77 \\
1996 & 0.55 & 0.28 & 9.25 & 1.64 & 1.09 & 0.28 & 13.10 \\
1997 & 0.54 & 0.26 & 9.80 & 1.54 & 1.10 & 0.25 & 13.50 \\
1998 & 0.51 & 0.27 & 10.32 & 1.00 & 1.10 & 0.24 & 13.44 \\
1999 & 0.61 & 0.29 & 10.65 & 1.10 & 1.10 & 0.25 & 14.00 \\
2000 & 0.57 & 0.27 & 11.10 & 1.52 & 1.13 & 0.25 & 14.84 \\
2001 & 0.50 & 0.31 & 11.46 & 1.33 & 1.26 & 0.26 & 15.12 \\
2002 & 0.48 & 0.32 & 11.56 & 1.30 & 1.35 & 0.27 & 15.29 \\
2003 & 0.51 & 0.29 & 10.95 & 1.36 & 1.42 & 0.25 & 1478 \\
2004 & 0.49 & 0.32 & 10.58 & 1.69 & 1.44 & 0.25 & 14.78 \\
\hline
\end{tabular}

Fuente: Elaboración propia con base en Bureau of Census de Estados Unidos. 
Por lo demás, como se observa en el cuadro 7, Colombia es un proveedor marginal del comercio de los Estados Unidos, puesto que contribuye con el 0,49\% del total de las importaciones estadounidenses. Este nivel de participación es apenas una fracción del correspondiente a México, y muy inferior a Brasil, pero superior al de Chile o Argentina, países éstos que tienen un comercio exterior más diversificado geográficamente. (cuadro 7).

\subsection{Condiciones de acceso las exportaciones colombianas al mercado de Estados Unidos}

Como ya se ha sugerido, las exportaciones colombianas a Estados Unidos son en su mayoría, de origen primario y están altamente concentradas al punto de que sólo 8 productos primarios representan cerca del $75 \%$ del total (cuadro 8).

La mayor parte de tales mercancías goza en la actualidad, de ingreso libre en el mercado estadounidense bien sea en virtud del ATPDEA (cuadro 8), o porque la tarifa NMF ya está en cero en Estados Unidos. Se estima que el arancel ponderado que aplica este país a las importaciones procedentes de Colombia es del orden del 1\%, y el nivel NMF es del orden del 3\% (el aplicable a México es 0,34\%).

Ahora bien, como el ATPDEA se vence en 2006, la principal justificación del TLC en la perspectiva del gobierno colombiano, es extender indefinidamente en el tiempo, el acceso preferencial al mercado estadounidense. Esta garantía podría surtir además, un efecto seguridad para estimular las inversiones en producciones de exportación a Estados Unidos.

El otro beneficio eventual del TLC, podría ser el la inclusión de los pocos productos que no están actualmente beneficiados por el ATPDEA, algunos de los cuales, tienen registros y (potencial), exportables significativos. Este es principalmente, el caso de algunas confecciones textiles, algunos productos de la pesca y frutas y legumbres.

Así las cosas, los beneficios que puede obtener Colombia en términos de exportaciones, no parece ser significativos al tomar en cuenta, sólo los niveles arancelarios de Estados Unidos. Lo que ocurre es que las ventas colombianas a este mercado, están sujetas a toda clase de barreras no arancelarias (BNA).

Las BNA se definen como (DEARdofF, 2004)26: "leyes, regulaciones, políticas o prácticas de un país que restringen el acceso de productos importados a su merca-

26 Deardoff, Alan, 2004, Deardoff's Glossary of International Economics, http://www-personal.umich.edu/ alandear/glossary/. 
REVISTA DE RELACIONES INTERNACIONALES, ESTRATEGIA Y SEGURIDAD

do". Como se ve, las BNA incluyen normas legales como procedimientos administrativos no basados en normas explícitas, sino en prácticas y directivas informales de los gobiernos y sus agencias especializadas. En el caso concreto de Estados Unidos, cerca de un $34 \%$ de las posiciones arancelarias que representan el $27 \%$ del valor de las importaciones, están afectadas por las BNA (cuadro 9).

\section{Cuadro 8}

Colombia: principales productos de exportación a Estados Unidos: exportaciones (millones de dólares) y participaciones

\begin{tabular}{|c|c|c|c|c|c|}
\hline & 2001 & 2002 & $\begin{array}{c}2003 \\
01-03\end{array}$ & Promedio & $\begin{array}{c}\text { Participación } \\
\text { promedio 01-03 }\end{array}$ \\
\hline Total & 5255 & 5160 & 5798 & 5404 & 100.0 \\
\hline Productos primarios & 4092 & 4033 & 4043 & 4056 & 75.1 \\
\hline Café & 244 & 258 & 290 & 264 & 4.9 \\
\hline Petróleo & 2316 & 2253 & 2055 & 2208 & 40.9 \\
\hline Derivados del petróleo & 556 & 535 & 568 & 553 & 10.2 \\
\hline Carbón & 303 & 230 & 384 & 305 & 5.6 \\
\hline Ferroníquel & 12 & 16 & 23 & 17 & 0.3 \\
\hline Banano & 133 & 143 & 130 & 135 & 2.5 \\
\hline Flores & 482 & 545 & 550 & 526 & 9.7 \\
\hline Esmeraldas & 47 & 54 & 45 & 49 & 0.9 \\
\hline Otros agropecuarios & 91 & 83 & 79 & 84 & 1.6 \\
\hline Camarones & 10 & 11 & 6 & 9 & 0.2 \\
\hline Demás agropecuarios & 80 & 70 & 71 & 74 & 1.4 \\
\hline Franjas & 1 & 2 & 2 & 2 & 0.0 \\
\hline Demás mineros & 85 & 177 & 552 & 271 & 5.0 \\
\hline Industriales & 985 & 866 & 1115 & 989 & 18.3 \\
\hline Agroindustriales & 97 & 123 & 154 & 125 & 2.3 \\
\hline Azúcar & 19 & 15 & 31 & 22 & 0.4 \\
\hline Productos del café & 25 & 30 & 24 & 26 & 0.5 \\
\hline Demás agroindustriales & 50 & 70 & 91 & 70 & 1.3 \\
\hline Franjas & 2 & 8 & 8 & 6 & 0.1 \\
\hline Industria liviana & 470 & 524 & 739 & 578 & 10.7 \\
\hline Confecciones & 272 & 284 & 436 & 331 & 6.1 \\
\hline Textiles & 39 & 17 & 20 & 25 & 0.5 \\
\hline Editoriales & 7 & 10 & 16 & 11 & 0.2 \\
\hline Calzado & 5 & 3 & 4 & 4 & 0.1 \\
\hline Manufacturas de cuero & 28 & 26 & 25 & 26 & 0.5 \\
\hline Productos de plástico & 16 & 43 & 52 & 37 & 0.7 \\
\hline Jabones cosméticos, otros & 4 & 4 & 4 & 4 & 0.1 \\
\hline Demás industria liviana & 98 & 138 & 182 & 139 & 2.6 \\
\hline Industria básica & 332 & 152 & 124 & 203 & 3.8 \\
\hline Metalúrgica & 56 & 49 & 66 & 57 & 1.1 \\
\hline Química básica & 258 & 93 & 46 & 132 & 2.5 \\
\hline Papel & 18 & 10 & 12 & 13 & 0.2 \\
\hline Maquinaria y equipo & 85 & 65 & 94 & 81 & 1.5 \\
\hline Industria automotriz & 2 & 2 & 3 & 3 & 0.0 \\
\hline Demás productos & 1 & 1 & 9 & 4 & 0.1 \\
\hline
\end{tabular}

Fuente: Elaboración propia con base en información disponible en el sitio web del Ministerio de Comercio, Industria y Turismo. 


\footnotetext{
EL TLC DE COLOMBIA CON ESTADOS UNIDOS Y SUS IMPLICACIONES EN LOS DEPARTAMENTOS COLOMBIANOS
}

\section{Cuadro 9}

\section{Incidencia de las restricciones no arancelarias en Estados Unidos}

\begin{tabular}{l|r}
\hline Total de posiciones en el nomenclador & $\mathbf{1 0 . 1 0 2}$ \\
Importaciones totales (US\$ millones, 1997) & $\mathbf{8 4 1 . 6 9 0}$ \\
\hline Posiciones con restricciones no arancelarias & $\mathbf{3 . 4 6 8}$ \\
Participación en el total & $34 \%$ \\
Importaciones totales con restricciones no arancelarias & 225.837 \\
Participación en el total & $27 \%$ \\
Posiciones con restricciones no arancelarias "núcleo" & 1.791 \\
Participación en el total & $18 \%$ \\
Importaciones totales con restricciones no arancelarias "núcleo" & 65.793 \\
Participación en el total & $8 \%$ \\
Restricciones no arancelarias "núcleo" & \\
Licencias de importación no automáticas & $70 \%$ \\
Cuotas & $20 \%$ \\
Medidas antidumping y compensatorias & $5 \%$ \\
Aranceles estacionales & $3 \%$ \\
Prohibiciones de importación & $1 \%$ \\
Participación de posiciones con restricciones no arancelarias en el total & \\
Productos primarios & \\
Manufacturas de origen agropecuario & $74 \%$ \\
Manufacturas de origen industrial & $76 \%$ \\
Combustibles & $25 \%$ \\
Participación de restricciones no arancelarias “núcleo" en el total de las & $25 \%$ \\
posiciones con restricciones no arancelarias & \\
Productos primarios & \\
Manufacturas de origen agropecuario & \\
Manufacturas de origen industrial & \\
Combustibles & $90 \%$ \\
& $22 \%$ \\
\hline
\end{tabular}

Fuente: Bouzas et al. (2002), Las relaciones comerciales Argentina - Estados Unidos en el marco de las negociaciones comerciales del ALCA, Serie Estudios y Perspectivas, CEPAL Oficina de Buenos Aires.

Algunas de las BNA que dificultan el acceso al mercado estadounidense son: regulaciones y normas ambientales; costos de importación; sellos de calidad y otros requerimientos tecnológicos; medidas antidumping; y medidas de apoyo interno. De estas barreras, las más relevantes para Colombia son las tecnológicas, las cuotas y muy especialmente las medidas de apoyo interno a la agricultura (MARTín y RAMíREZ, op. cit.)

En cuanto al último tipo de BNA antes mencionado, ellas están enmarcadas en la Ley Agrícola de Estados Unidos de 2002 (FARM BILL), que estableció subsidios de US 180.000 millones entre 2003 y 2009. Gracias a estos subsidios, Estados Unidos 
puede competir internacionalmente con productos como algodón, arroz, leche, maíz y oleaginosas, en los cuales, no tiene ventajas comparativas (Ministerio de Agricultura y Desarrollo Rural, 2004).

Las medidas de apoyo interno a la agricultura afectan los intereses colombianos de varias maneras: a) dificultan el acceso de sus exportaciones agrícolas al mercado estadounidense, b) la producción subsidiada presiona a la baja, los precios en los mercados mundiales y c) la producción subsidiada compite en forma desleal en el mercado doméstico y en terceros mercados ${ }^{27}$.

\subsection{Las importaciones colombianas procedentes de Estados Unidos}

Al contrario de lo ocurrido con las exportaciones, Estados Unidos ha perdido participación como proveedor del mercado colombiano (cuadro 10).

\begin{tabular}{|c|c|c|c|}
\hline \multicolumn{4}{|c|}{$\begin{array}{c}\text { Cuadro } 10 \\
\text { Participación de Estados Unidos en las importaciones colon } \\
\text { Millones de dólares }\end{array}$} \\
\hline & USA & Totales & \% USA \\
\hline 1991 & 1.722 & 5.086 & 33.9 \\
\hline 1992 & 2.325 & 6.513 & 35.7 \\
\hline 1993 & 3.246 & 9.832 & 33.0 \\
\hline 1994 & 3.805 & 11.943 & 31.9 \\
\hline 1995 & 4.660 & 13.861 & 33.6 \\
\hline 1996 & 4.809 & 13.675 & 35.2 \\
\hline 1997 & 5.397 & 15.379 & 35.1 \\
\hline 1998 & 4.682 & 14.677 & 31.9 \\
\hline 1999 & 3.952 & 10.659 & 37.1 \\
\hline 2000 & 3.893 & 11.539 & 33.7 \\
\hline 2001 & 4.414 & 12.821 & 34.4 \\
\hline 2002 & 4.038 & 12.717 & 31.8 \\
\hline
\end{tabular}

Fuente: elaboración propia con base en DANE.

27 Para un completo análisis de la Farm Bill véase: BASCO, CARLO et al. (2003), La nueva ley de seguridad agrícola y de inversión rural de los Estados Unidos (Farm Bill). Un análisis de las implicaciones comerciales, Serie Comercio Internacional 41, CEPAL, Santiago de Chile. 
El correlato lógico con respecto de las importaciones del modelo de ventaja comparativa que rige el intercambio bilateral, es que las compras a Estados Unidos están constituidas en forma mayoritaria, por bienes industriales (cuadro 11), al punto de que la tasa de penetración de las importaciones industriales con dicho origen, alcanza niveles del $30 \%$ (cuadro 12).

\section{Cuadro 11}

Composición de importaciones desde usa por sector

\begin{tabular}{lrrrrrrrrrrrr}
\hline & 1991 & 1992 & 1993 & 1994 & 1995 & 1996 & 1997 & 1998 & 1999 & 2000 & 2001 & 2002 \\
\hline Agropec. & 4 & 5 & 4 & 5 & 6 & 10 & 7 & 8 & 8 & 8 & 7 & 10 \\
Minería & 1 & 1 & 0 & 0 & 0 & 0 & 0 & 0 & 0 & 0 & 0 & 0 \\
Industria & 95 & 93 & 95 & 95 & 93 & 90 & 93 & 92 & 92 & 91 & 90 & 90 \\
Otros & 0 & 0 & 0 & 0 & 0 & 0 & 0 & 0 & 0 & 0 & 0 & 0 \\
\hline
\end{tabular}

Fuente: Elaboración propia con base en DANE.

\section{Cuadro 12}

Penetración de importaciones por sector con USA

\begin{tabular}{lrrrrrrrrrrrr}
\hline & $\mathbf{1 9 9 1}$ & $\mathbf{1 9 9 2}$ & $\mathbf{1 9 9 3}$ & $\mathbf{1 9 9 4}$ & $\mathbf{1 9 9 5}$ & $\mathbf{1 9 9 6}$ & $\mathbf{1 9 9 7}$ & $\mathbf{1 9 9 8}$ & $\mathbf{1 9 9 9}$ & $\mathbf{2 0 0 0}$ & $\mathbf{2 0 0 1}$ & $\mathbf{2 0 0 2}$ \\
\hline Agropec. & 0.79 & 1.29 & 1.34 & 1.45 & 2.33 & 3.89 & 2.69 & 2.90 & 2.83 & 3.01 & 3.10 & 3.98 \\
Minería & 0.48 & 0.46 & 0.45 & 0.51 & 0.35 & 0.37 & 0.47 & 0.41 & 0.23 & 0.19 & 0.21 & .022 \\
Industria & 18.35 & 22.10 & 29341 & 29.43 & 31.74 & 30.76 & 34.10 & 31.00 & 30.25 & 28.96 & 34.44 & 30.63 \\
\hline
\end{tabular}

Fuente: Elaboración propia con base en DANE.

\section{IMPLICACIONES DEL TLC CON LOS ESTADOS UNIDOS PARA LOS DEPARTAMENTOS COLOMBIANOS}

En esta sección, se intenta hacer un análisis de los posibles efectos del TLC sobre las economías departamentales, desde el punto de vista del aprovechamiento de las oportunidades de exportación, y desde la perspectiva del impacto del aumento de las importaciones sobre la producción doméstica regional.

\subsection{Las oportunidades de exportación}

En principio, es lógico suponer que las economías departamentales que en mayor medida podrían beneficiarse del TLC, son aquéllas que actualmente tienen una mayor proyección comercial hacia el mercado de Estados Unidos. Este es el caso de 
los departamentos exportadores de productos del sector minero: petróleo (Arauca, Casanare, Meta y Putumayo), carbón (La Guajira y Cesar), ferroníquel (Córdoba), oro (Antioquia, Santander y Valle), y esmeraldas (Boyacá). De igual manera, podría haber efectos positivos para los productores de bienes agropecuarios como café (Eje Cafetero), banano (Antioquia y Magdalena), y pesca (región Caribe); productos agroindustriales como flores (Cundinamarca y Antioquia), y manufacturas como textiles y confecciones (Antioquia, Bogotá, Valle y Atlántico), confitería (Valle y Caldas), cemento (Atlántico, Bolívar y Sucre), plásticos (Bolívar), y papel y editoriales (Valle, Bogotá y Cundinamarca).

Por otra parte, también existe la posibilidad — como se anotó supra— de que el TLC facilite la apertura y desarrollo del mercado estadounidense para productos que actualmente no gozan de franquicia arancelaria. Entre éstos, se destacan los forestales (producidos en Amazonia, Orinoquia y Córdoba), aceite de palma (Meta, Cesar y Magdalena), frutas y legumbres (Cundinamarca, Huila, Antioquia y Boyacá), algunas confecciones (Antioquia, Valle, Bogotá y Atlántico), y mariscos y crustáceos (región Caribe).

No obstante, el alcance de los beneficios potenciales mencionados, difiere mucho de producto a producto y de departamento a departamento. Así, en algunos casos como el del petróleo, por ejemplo, la capacidad de respuesta exportadora es muy limitada (casi inexistente, de no mediar el descubrimiento de nuevos yacimientos).

En la misma situación, aunque por razones diferentes, están las esmeraldas, el café, el banano, el azúcar e incluso las flores. En otros, como en los de carnes y lácteos y frutas y hortalizas, el efectivo aprovechamiento de las oportunidades depende crucialmente de la remoción de las BNA que impone Estados Unidos a la importación de dichos productos, lo cual es un tema en el que hasta ahora, no se ha hecho ningún avance significativo en la negociación ${ }^{28}$.

En todo caso, el impacto positivo del mantenimiento, ampliación o el desarrollo de nuevos mercados, dependerá, por supuesto, del peso que tengan los productos exportables en las respectivas economías departamentales.

Una sinopsis de los aspectos discutidos en este estudio, se presenta en las tablas 3 y 4 , en las cuales se observa que prácticamente el único renglón que podría crecer como consecuencia del TLC, es el de textiles y confecciones. Esto beneficiaría a los departamentos en donde está localizada tal industria, que son Antioquia, BogotáCundinamarca, Valle del Cauca y Atlántico, principalmente. Los demás productos,

28 Los Estados Unidos han mantenido a ultranza que los asuntos relacionados con la política agrícola los discutirá en el marco de la OMC. 
que podrían resultar beneficiados, están sujetos a las BNA o pertenecen a sectores en los cuales, el país no tiene ventajas comparativas fuertes ni la capacidad de aumentar en forma sustancial, la producción.

En síntesis, todo lo anterior quiere decir que no se puede esperar que el TLC tenga efectos positivos sustanciales en los departamentos colombianos.

\subsection{La vulnerabilidad departamental frente al eventual aumento de las importaciones}

Hay básicamente, dos tipos de bienes cuya importación desde Estados Unidos, podría aumentar como consecuencia del TLC: competitivos con la producción doméstica y complementarios con ella. Entre los primeros, están varios de los cuales, Colombia tiene capacidad de exportar al mercado estadounidense, es decir, que en estos sectores hay comercio intraindustrial, y entre los segundos, se cuentan los bienes intermedios y de capital requeridos por la producción nacional (cuadro 11 supra).

En la medida en que la segunda de las categorías mencionadas, tiene en Colombia aranceles que actualmente ya son muy bajos y su demanda depende de la dinámica de la actividad económica local; el incremento de las importaciones no tiene efectos adversos. Distinto es el caso de los bienes que compiten con la producción nacional, los cuales son por lo general, materias primas de origen agropecuario y bienes de consumo.

Entre estos últimos, como ya se dijo, hay varios como oleaginosas, molinería, cemento, papel y editoriales que pertenecen a sectores o cadenas en los cuales, Colombia realiza exportaciones a Estados Unidos, configurando una situación de comercio intraindustrial.

Ahora bien, según las estadísticas de importación del DANE (cuadro 16 de la tercera parte), más del $50 \%$ de las importaciones totales del país, están concentradas en Bogotá, Cundinamarca, Antioquia, Valle, Bolívar y Atlántico, con un fuerte predominio de los dos primeros departamentos ${ }^{29}$. Así las cosas, éstas serían las economías departamentales que sufrirían directamente la presión competitiva de las importaciones provenientes de Estados Unidos. No obstante, los efectos indirectos se extenderían a los departamentos de especialización agropecuaria que producen bienes importables. Entre éstos están Antioquia, Meta, Cesar, Magdalena, Bogotá, Bolívar, Atlántico, Sucre y Valle.

29 La excesiva concentración de las importaciones en Bogotá puede deberse a que se registren en esta localidad, mercancías que se dirigen a otros destinos dentro del país. 


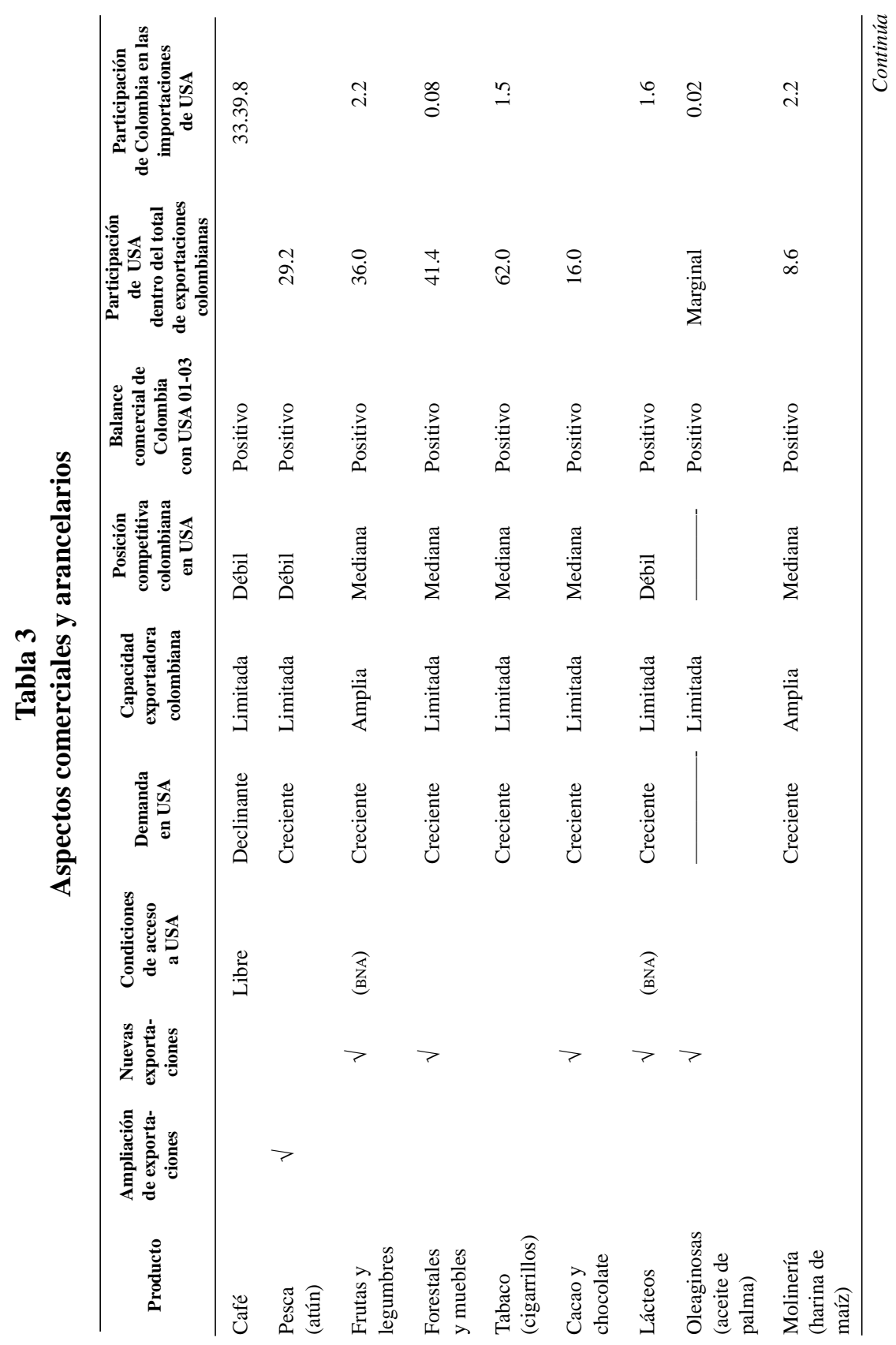


EL TLC DE COLOMBIA CON ESTADOS UNIDOS Y SUS IMPLICACIONES EN LOS DEPARTAMENTOS COLOMBIANOS

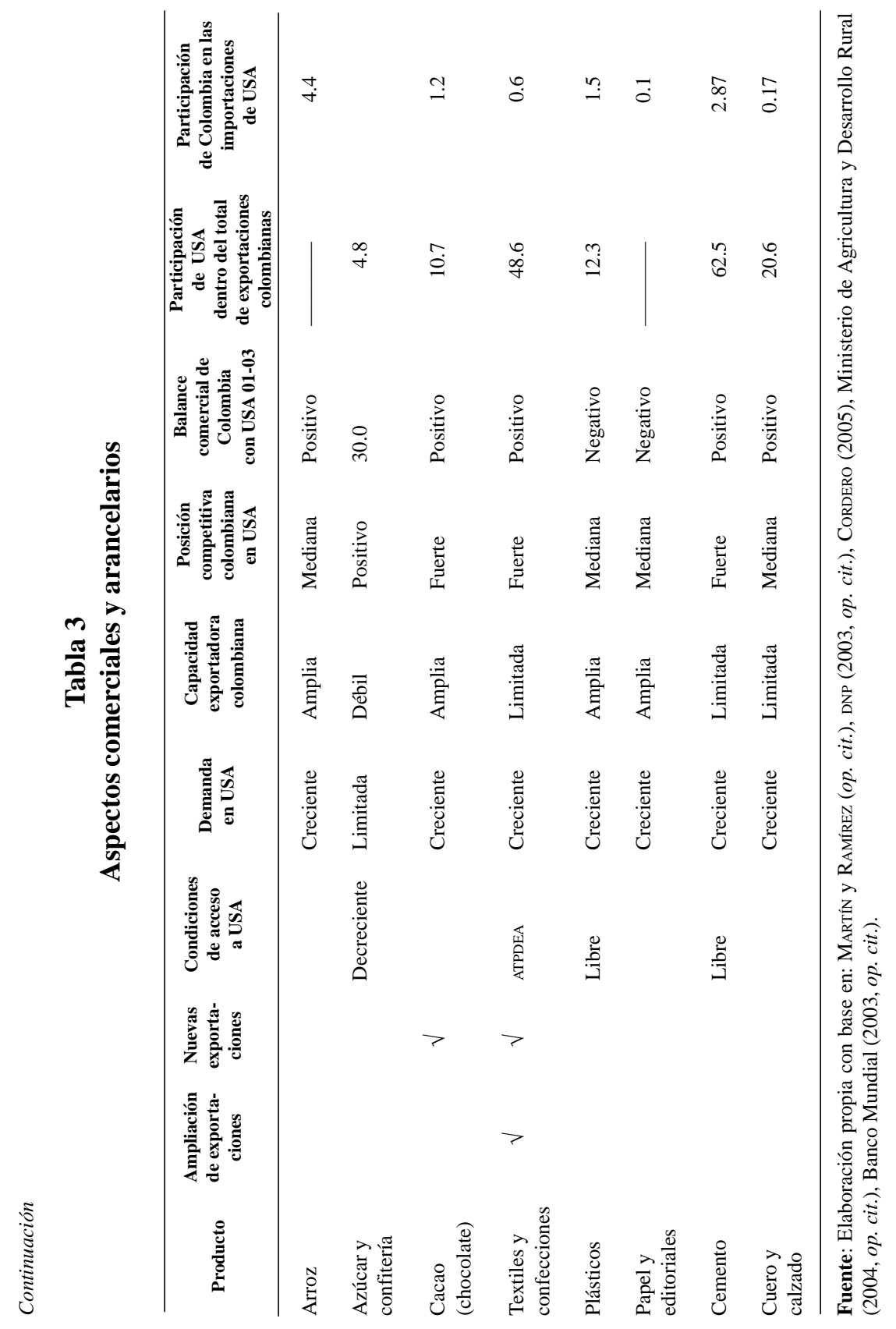




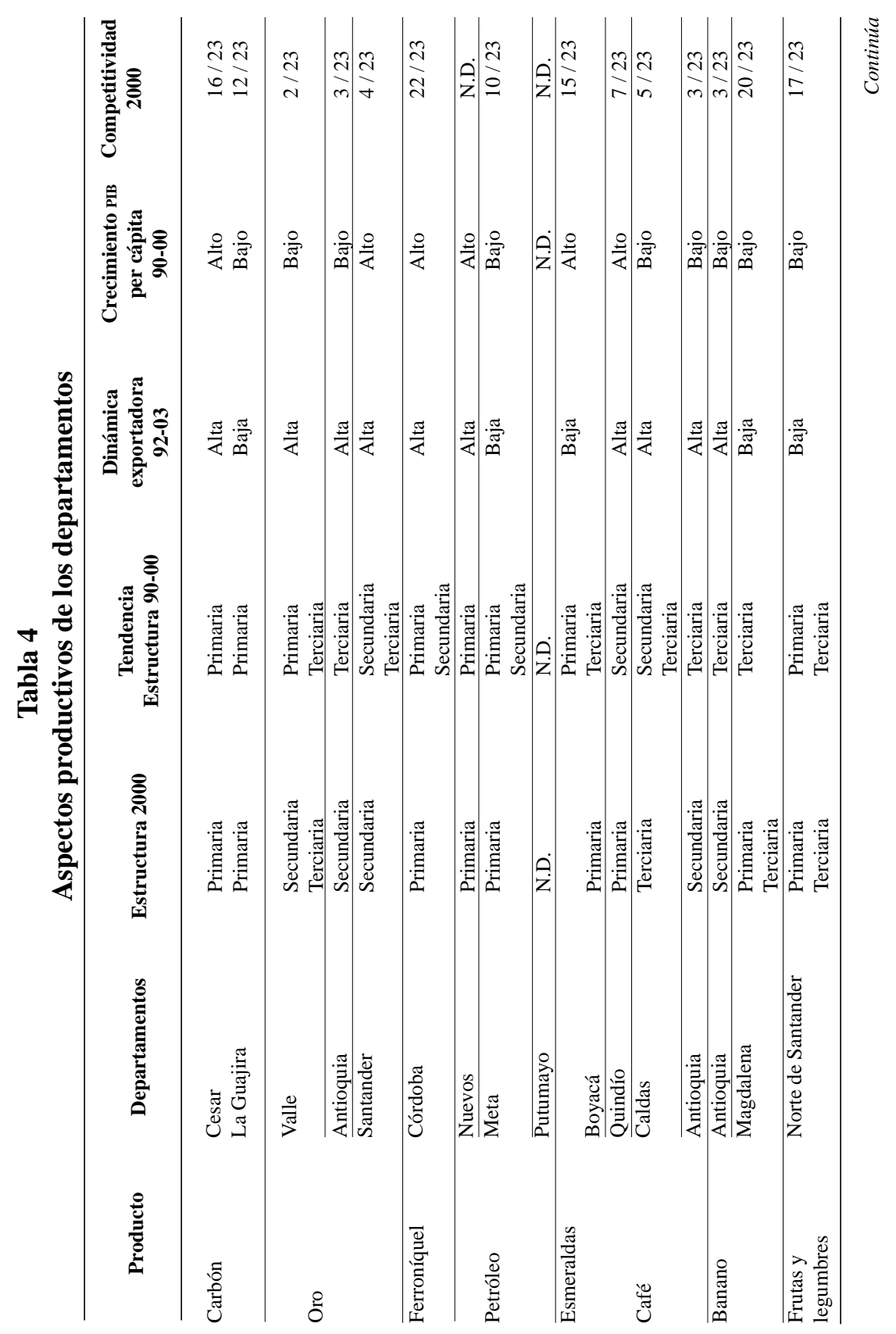




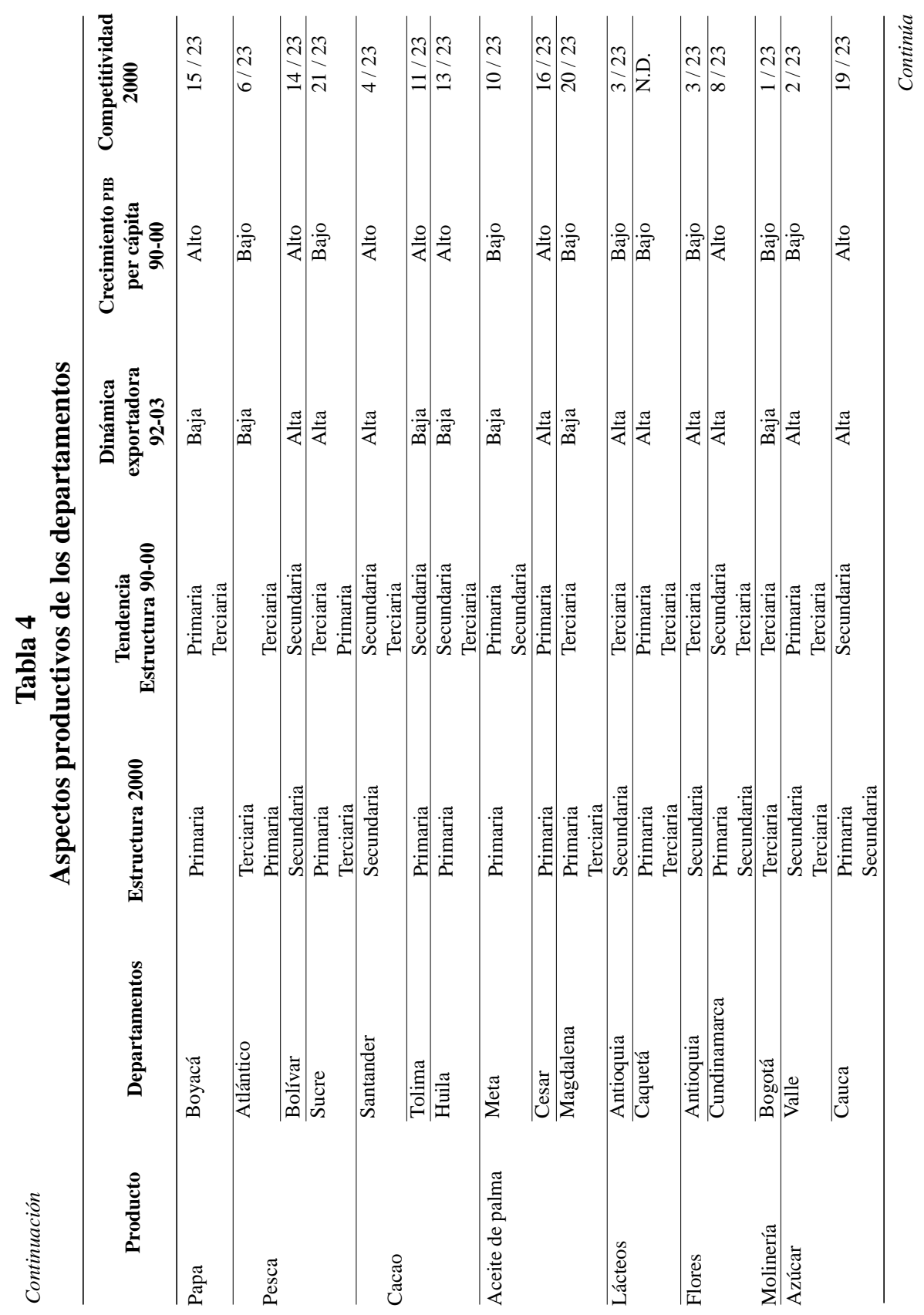




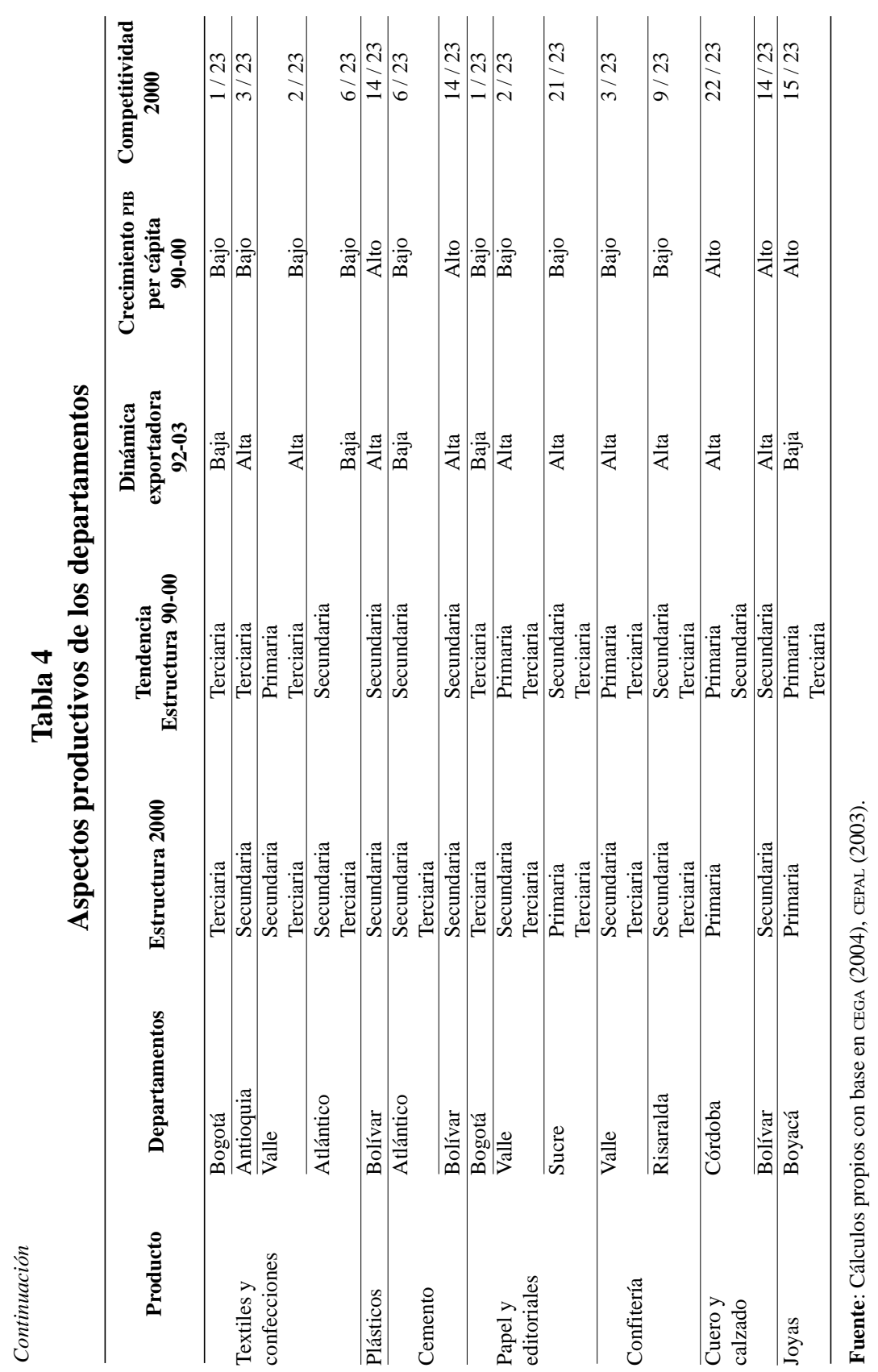




\section{COMENTARIOS FINALES}

La firma de un TLC con Estados Unidos, representa para Colombia la consolidación del modelo económico de apertura que se inició a principios de los años noventa y la definitiva gravitación del país hacia la economía estadounidense.

En balance, la estrategia de la apertura ha sido hasta ahora, decepcionante y de acuerdo con el análisis realizado en este documento, no es realista esperar que el TLC vaya a representar beneficios importantes para el desarrollo nacional. Antes bien, lo que se detecta es el riesgo de que los desajustes estructurales de la economía colombiana (bajo crecimiento, involución del cambio sectorial, desempleo, pobreza y mala distribución del ingreso), continúen agravándose y que los reforzados patrones de intercambio comercial con Estados Unidos, resulten inequitativos desde la perspectiva de las economías regionales colombianas.

\section{BIBLIOGRAFÍA}

BALDWIn, RichaRd. A domino theory of regionalism. Working Paper 4465. Cambridge: NBER, 1993.

BASCO, CARLO et al. La nueva ley de seguridad agrícola y de inversión rural de los Estados Unidos (Farm Hill). Un análisis de las implicaciones comerciales. Serie Comercio Internacional 41. Santiago de Chile: CEPAL, 2003.

BID. Más allá de las fronteras. El nuevo regionalismo en América Latina. Informe de progreso económico y social en América Latina. Washington: 2002.

BID y CEPAL. La liberación del comercio en el hemisferio occidental. Washington: 2005.

Blanco, Herminio y Zabludovsky, Jaime. Alcances y límites de la negociación del Acuerdo de Libre Comercio de las Américas. Documento de Trabajo IECI - 01. Buenos Aires: BID/INTAL, 2003.

Botero, Jesús y López, Hugo. Impactos del tLC sobre el empleo. En: Planeación y Desarrollo, vol. XXXVI (1). Bogotá: DNP, 2005.

BOUZAs, RoBerto et al. Las relaciones comerciales Argentina - Estados Unidos en el marco de las negociaciones del ALCA. Serie Estudios y Perspectivas 6. Buenos Aires: CEPAL, 2002.

Bussolo, Mauricio y Roland-Holst, David. Colombia y el trcan. Integración y comercio. Buenos Aires: INTAL/BID, 2004.

Cabezas, Mabel. Tratado de Libre Comercio entre Chile y Estados Unidos: revisión de estudios que cuantifican su impacto. Documentos de Trabajo 239. Santiago: Banco Central de Chile, 2003.

Cáceres, Enrique y Subarzo, Horacio. Diez años del tlcan de México: una perspectiva analítica. México: Fondo de Cultura Económica, 2004.

CÁrdenas, Miguel Eduardo. Coordinador. El futuro de la integración andina. Bogotá: Fescol/CEReC, 2004.

Chumacero, Rómulo et al. Chile's Free Trade Agreements. How Big is the Deal? Documentos de Trabajo 264. Santiago: Banco Central de Chile, 2004. 
Clavijo, Sergio. Crecimiento, comercio internacional e instituciones: reflexiones a partir de las negociaciones TLC-ALCA. Borradores de Economía 307. Bogotá: Banco de la República, 2004.

De la Rosa, JuAn RamiRo. Relaciones entre apertura y crecimiento en México, Comercio Exterior 51 (5). México: Banco de Comercio Exterior, SNC, 2001.

Deardoff, Alan. Deardoff's Glossary of International Economics, http://www.personal.unice.edu/ alandear/glossary/, 2004.

DeVlin, Robert y EsteVAdEORdal, Antony. What's new in the new regionalism in the Americas? Working Paper 6. Buenos Aires: INTAL-ITD-STA, 2001.

DORnBush, Rudiger. Relaciones comerciales norte-sur en las Américas: el argumento a favor del libre comercio. Washington: BID, CEPAL, 1995.

FESCOL. Costos y beneficios del TLC con Estados Unidos. Lima: Friedrich Ebert Stiftung/ Red Latinoamericana de Comercio Internacional (LATN), 2002-2003. Bogotá: Gente Nueva, 2005.

- Anuario social, político y económico de Colombia. Síntesis. 2002-2003. Bogotá: Gente Nueva, 2004.

García, Adolfo et al. Colombia-Estados Unidos: una agenda en función de la seguridad. Bogotá: FESCOL, 2004.

Gaviria, Alejandro. Los efectos sociales del tlc. En: Planeación y Desarrollo, vol. XXXVI (1). Bogotá: DNP, 2005

Kose, M. Ayhan et al. How Has nafta Affected the Mexican Economy? Review and Evidence. Working Paper 05 / 59. Washington: IMF, 2004.

Lederman, DANiEl et al. Lessons from NAFTA for Latin America and the Caribbean. Washington: Banco Mundial / Stanford University Press, 2005.

Martín, Clara Patricia y Ramírez, Juan Mauricio. Impacto económico de un acuerdo de libre comercio entre Colombia y Estados Unidos. En: Borradores de Economía 326. Bogotá: Banco de la República, 2005.

Ministerio de Agricultura y Desarrollo Rural. El agro colombiano frente al TLC con los Estados Unidos. Bogotá: Bolsa Nacional Agropecuaria, 2004.

Ministerio de Comercio, Industria y Turismo. Editor Juan Carlos Ramírez. ¿Por qué negociar tratados de libre comercio? Bogotá: 2005.

Moncayo, Edgard. Hacia una renovación de los contenidos de la integración andina. En: CÁRDENAS, Miguel EduARDo, op cit.

Las relaciones externas de la comunidad andina. Lima: Secretaria General CAN, 1999. PÁgINA Internet de la CAN: www.comunidadandina.org.

Morley, Samuel A. y Díaz-Bonilla, Carolina. México: ¿se benefician de la apertura los pobres? En: GANuZa, EnRiQue et al. México: 2004.

Pardo, Magdalena et al. El comercio al servicio de la seguridad. Bogotá: Fescol, 2004.

Puyana, Alicia. El camino mexicano hacia el regionalismo abierto: los acuerdos de libre comercio de México con América del Norte y Europa”. Serie Comercio Internacional 35. Santiago: CEPAL, 2003.

Tornell, AARón et al. NAFTA and Mexico's Less than Stellar Performance, Working Paper 10289. Cambridge: NBER, 2004. 
EL TLC DE COLOMBIA CON ESTADOS UNIDOS Y SUS IMPLICACIONES EN LOS DEPARTAMENTOS COLOMBIANOS

Umaña, Germán. Análisis del Tratado de Libre Comercio Chile - Estados Unidos. Lima: Secretaría de la Comunidad Andina, 2003.

VAUGhan CARO, Daniel. Tratado de Libre Comercio y barreras no arancelarias: un análisis crítico. Archivos de Economía 281. Bogotá: DNP.

Venegas-Martínez, Francisco. El tlcan y su efecto en la inversión extranjera de cartera. En: Cáceres, Enrique y Subarzo, Horacio, op. cit.

Villamil, Jesús Alberto y Estupiñán, Fernando. Acuerdos regionales de integración en el hemisferio americano post - tLCAN: un análisis comparativo. En: EConomía y Desarrollo, vol. 3 (2). Bogotá: Universidad Autónoma de Colombia, 2004.

Villarreal, René. tlcan 10 años después. Experiencia de México y lecciones para Colombia y América Latina. México: CECIC, 2004. 